Meta

Journal des traducteurs

Translators' Journal

\title{
Traduire le goût du vin... Quand le propre échappe au figuré
}

\section{Christine Demaecker}

Volume 60, numéro 2, août 2015

$60^{\mathrm{e}}$ anniversaire. Les horizons de la traduction : retour vers le futur

$60^{\text {th }}$ Anniversary. Translation's Horizons: Back to the Future

60mo aniversario. Los horizontes de la traducción: regreso al futuro

URI : https://id.erudit.org/iderudit/1032875ar

DOI : https://doi.org/10.7202/1032875ar

Aller au sommaire du numéro

Éditeur(s)

Les Presses de l’Université de Montréal

ISSN

0026-0452 (imprimé)

1492-1421 (numérique)

Découvrir la revue

Citer ce document

Demaecker, C. (2015). Traduire le goût du vin... Quand le propre échappe au figuré. Meta, 60(2), 324-324. https://doi.org/10.7202/1032875ar d'utilisation que vous pouvez consulter en ligne.

https://apropos.erudit.org/fr/usagers/politique-dutilisation/ 


\title{
Traduire le goût du vin... Quand le propre échappe au figuré
}

\author{
Christine Demaecker \\ Institut Supérieur de Traducteurs et Interprètes, Bruxelles, Belgique \\ cdemaecker@heb.be
}

En analysant les traductions français-anglais et anglais-français des deux grands guides du vin que sont Le Larousse des vins de France et le Parker's Wine Buyers' Guide, l'amateur de création d'images originales sera sans doute un peu déçu. En effet, si pratiquement tout le vocabulaire du goût du vin est métaphorique, les traductions semblent bien proches de l'original. Ces traductions seraient-elles vraiment sourcières, sans approche interprétative? La traduction du goût du vin devrait-elle coller aux mots pour ne pas perdre son sens? La démarche des professionnels est subtile.

Dans ce domaine de spécialité, l'appréhension du sens précis reste inaccessible, car seuls certains termes récurrents sont répertoriés dans les glossaires et les dictionnaires, et leurs définitions sont souvent vagues et circulaires. À cette liste des termes répertoriés s'ajoutent, par extension du vocabulaire, de nombreux quasi-synonymes dont le sens n’est jamais précisé.

Pour traduire le goût du vin, cette quête du sens ne peut passer que par l'analyse de sa conceptualisation. L'expression des perceptions sensorielles révèle des métaphores conceptuelles bien ancrées chez les spécialistes et les amateurs avertis. Pour chaque vin, ces conceptualisations sont combinées dans des intégrations conceptuelles singulières, qui passent d'une langue à l'autre avec plus ou moins de précision en fonction de leurs particularités langagières.

Si la traduction des termes peut paraître littérale, c'est qu'elle est soumise à une double contrainte: la traduction des termes répertoriés est figée, et celle des termes non définis ne peut ni générer trop de connotations nouvelles ni exprimer une conceptualisation absente chez les spécialistes dans la langue d'arrivée.

Dans un souci de pertinence, la traduction utilise les conceptualisations déjà ancrées dans la langue d'arrivée. Dans l'original comme dans la traduction, les métaphores des notes de dégustation ne répondent pas à un souci de précision. Elles ne se justifient que pour fournir des pistes de représentation de l'impression sensorielle. C'est le seul sens qu'elles véhiculent, si éloignées de l'explicite...

Après quelques années d'expérience en entreprise, Christine Demaecker enseigne depuis 1990 la traduction générale, la traduction spécialisée et la traduction à vue à l'Institut supérieur de traducteurs et interprètes à Bruxelles. À l'Université de Liège, elle termine une recherche sur la traduction des métaphores utilisées dans les notes de dégustation du vin. 